\title{
Low Power Energy Efficient DC-DC Converter for Energy Harvesting Applications
}

\author{
Bal krishan ${ }^{1 *}$ and Yogita Dahiya ${ }^{2}$ \\ $I^{*}$ AP, YMCA University of Science \& Tech., Faridabad, \\ (Haryana) - 121006, India \\ ${ }^{2}$ ASE, Tata Consultancy Services Ltd., Chennai, (Tamilnadu)-600097, India \\ ${ }^{1}$ kadiyan26@yahoo.com, 2yogitadahiya@gmail.com
}

\begin{abstract}
Nowaday's battery-free power sources are emerging which use environmental energy to fulfil the power requirement; these environmental energies are solar, vibrational, light and temperature difference. A transducer is required to convert this energy into an electrical signal. This electrical signal is converted to a constant DC with the help of power management system.Power management system's first stage TEG which converts the temperature difference into an electrical signal input voltage which may vary according to the temperature. Next stage is DC-DC boost converter which contains switches and switching frequency is controlled by the different mechanism used. This DC$D C$ boost converter supplies the constant $d c$ voltage at the output by removing the fluctuations and ripples, this also includes providing different gain so for the different input-output remains at a fixed level.
\end{abstract}

Index Terms: Battery charger, boost converter, $d c-d c$ converter, energy harvesting

\section{Introduction}

Wireless sensors are becoming popular in different field's applications like from agriculture (pervasive computing) to medical (health monitoring). These remote devices use non-renewable energy sources like ion batteries which need replacement time to time. The increasing demand for renewable energy has increased significantly over the years because of the shortage of fossil fuels and the greenhouse effect. For renewable energy, there are many sources like solar and some waste energy of vibration thermal etc.

In many technical applications, it is required to convert a set voltage DC source into a variable-voltage DC yield. A DC-DC switching converter converts voltage directly from DC to DC and is simply known as a DC Converter. A DC converter is equivalent to an AC transformer with a persistently factor turn's proportion. It can be utilized to step down or step up a DC voltage source, as a transformer.

In a boost converter, the output voltage is more prominent than the input voltage hence the name "boost". A boost converter using a power MOSFET is demonstrated as follow:

Received (March 24, 2017), Review Result (December 5, 2017), Accepted (December 14, 2017) 


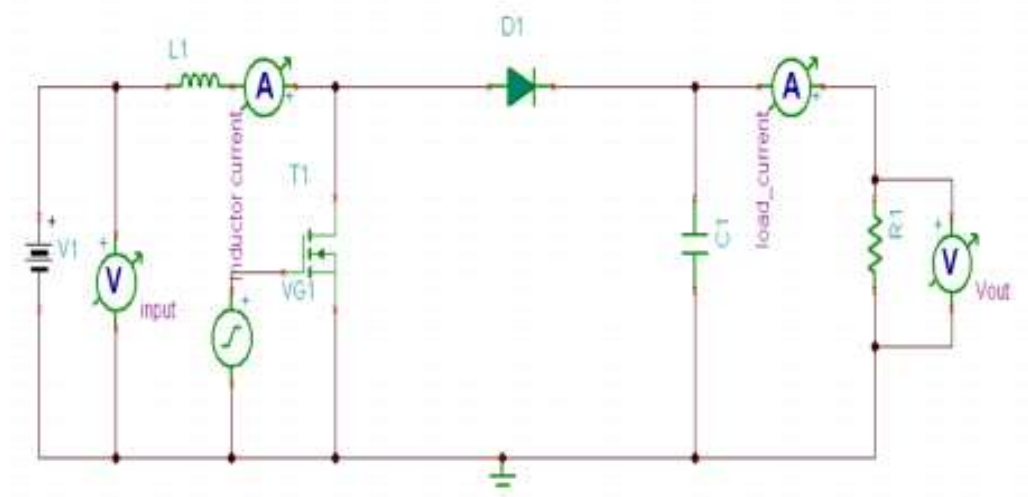

Figure 1. Circuit Diagram of Boost Converter

The function of boost converter can be divided into two modes on the basis of switching of transistor T1, Mode I (Switch ON) and Mode II (Switch OFF).

\subsection{Mode I (Switch ON)}

When the transistor $\mathrm{T} 1$ is switched on at time $\mathrm{t}=0$ and the charging of the inductor L1 find the minimal resistance path from the transistor $\mathrm{T} 1$.
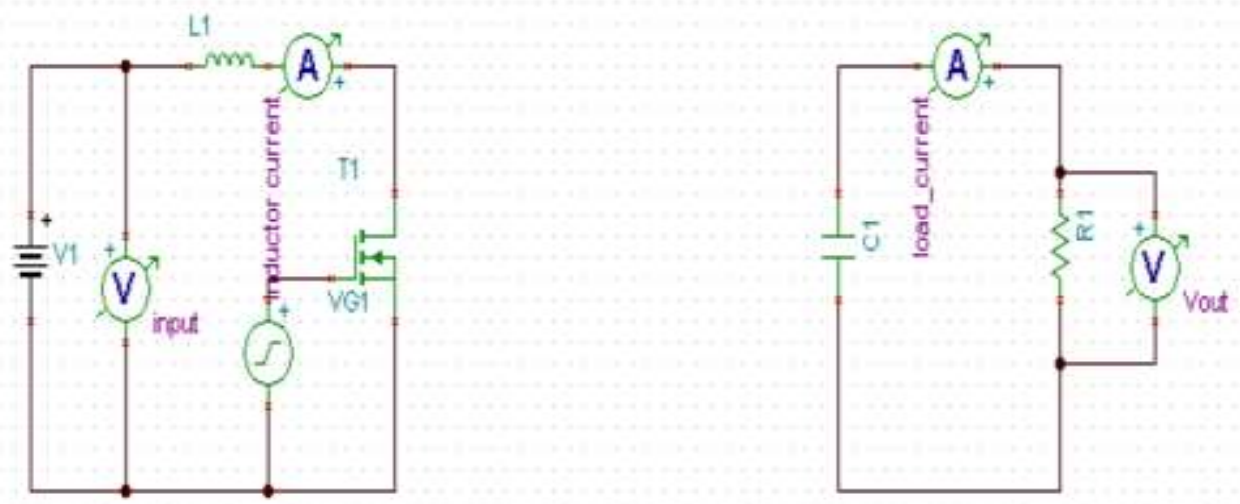

Figure 2. Circuit Diagram for Mode I

Diode D1 is also forward biased but the MOSFET offers less resistance than the combination of a diode, capacitance and load resistance.

The voltage-current relation for the inductor $\mathrm{L}$ is:

$$
\mathrm{i}=\frac{1}{\mathrm{~L}} \int_{0}^{\mathrm{t}} \mathrm{vdt}+\mathrm{io}
$$

Or

$$
\mathrm{V}=\frac{\mathrm{Ldi}}{\mathrm{dt}}
$$

For a constant rectangular pulse: 


$$
\mathrm{i}=\frac{\mathrm{vt}}{\mathrm{L}}+\mathrm{io}
$$

When the transistor $\mathrm{T} 1$ is switched $\mathrm{ON}$ current is:

$$
\begin{gathered}
\text { Ipk }=\frac{(\text { Vin }- \text { Vtrans }) \text { Ton }}{\mathrm{L}}+\text { io } \\
\Delta \mathrm{i}=\frac{(\text { Vin }- \text { Vtrans }) \text { Ton }}{\mathrm{L}}
\end{gathered}
$$

\subsection{Mode II (Switch OFF)}

When the transistor $\mathrm{T} 1$ is switched off at time $\mathrm{t}=\mathrm{t} 1$. The inductor does not allow an abrupt change in the current. Therefore diode D1 becomes forward biased and the input current now flows through inductor L1, capacitor $\mathrm{C} 1$ and load resistance $\mathrm{R} 1$. The inductor current falls until the next cycle. The energy stored in inductor L flows through the load.

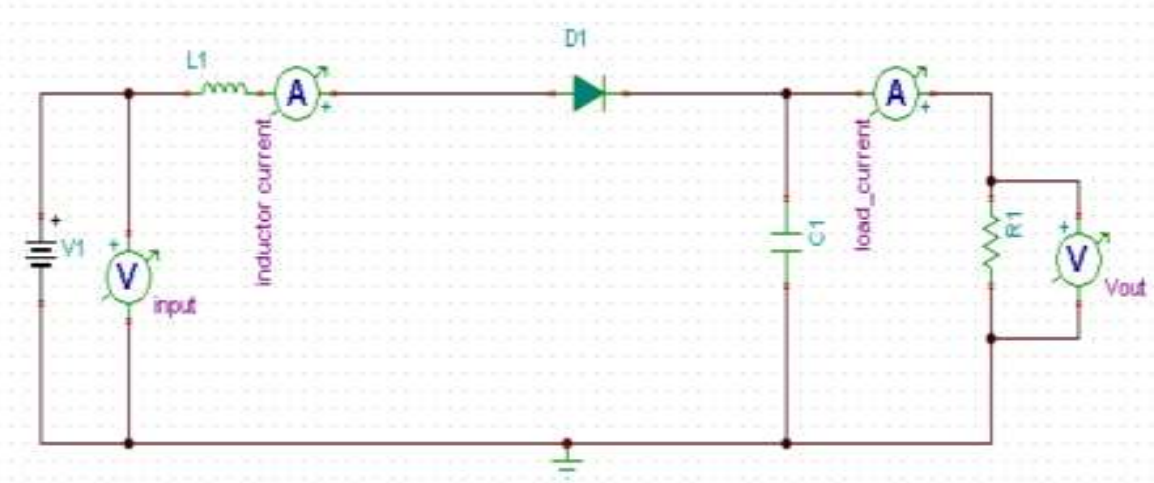

Figure 3. Circuit Diagram for Mode II

And when the transistor T1 is switched OFF the current is:

$$
\begin{gathered}
\text { Io }=\text { Ipk }-\frac{(\text { Vout }- \text { Vin }+ \text { Vd)Toff }}{L} \\
\Delta \mathrm{i}=\frac{(\text { Vout }- \text { Vin }+ \text { Vd)Toff }}{L}
\end{gathered}
$$

The waveforms of the voltages and currents are shown below: 


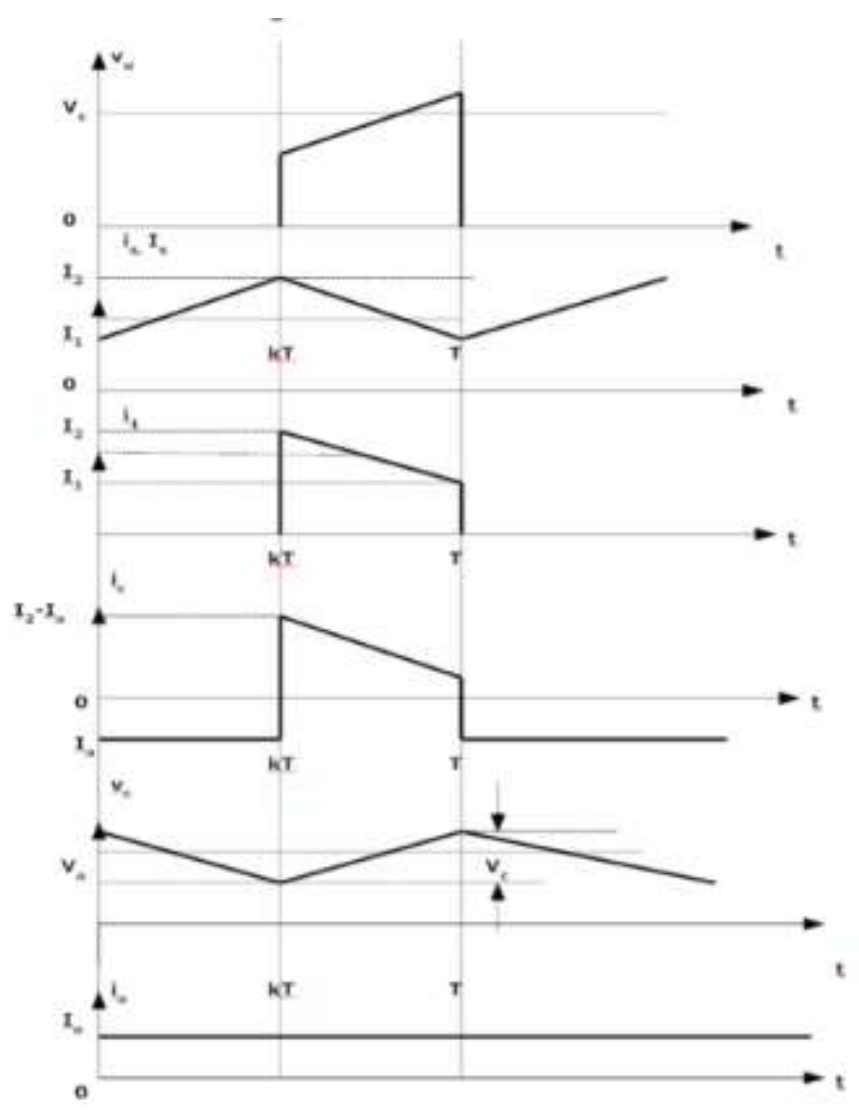

Figure 4. Waveforms [14]

By equating through $\Delta \mathrm{i}$, we can solve for Vout.

$$
\frac{(\text { Vin }- \text { Vtrans }) \text { Ton }}{\mathrm{L}}=\frac{(\text { Vout }- \text { Vin }+ \text { Vd }) \text { Toff }}{\mathrm{L}}
$$

Neglecting diode and transistor drop:

$$
\begin{gathered}
\text { Vin(Ton }+ \text { Toff })=\text { Vout } * \text { Toff } \\
\text { D }=\frac{\text { Ton }}{\text { Ton }+ \text { Toff }}
\end{gathered}
$$

$\mathrm{D}=$ Duty cycle

$$
\text { Vin }=\text { Vout } * \frac{\text { Toff }}{\text { Ton }+ \text { Toff }}
$$

Finally,

$$
\text { Vout }=\frac{\text { Vin }}{1-\mathrm{D}}
$$

So it is clear that the output voltage is related directly to the duty cycle of the switching frequency of transistor T1.

\section{Block Diagram of Boost Converter}

The voltage source provides the input DC voltage to the switch element and to the output. Comparator, Reference Voltage and Pulse Width Modulator (PWM) are the elements for controlling the switch. Comparator used to compare the output voltage and 
the reference voltage (desired output) and the difference is fed to the input of PWM. PWM generate the pulses of the different widths according to the input. The output of the PWM is given to the transistor (switching element).

The basic blocks of building a boost converter circuit:

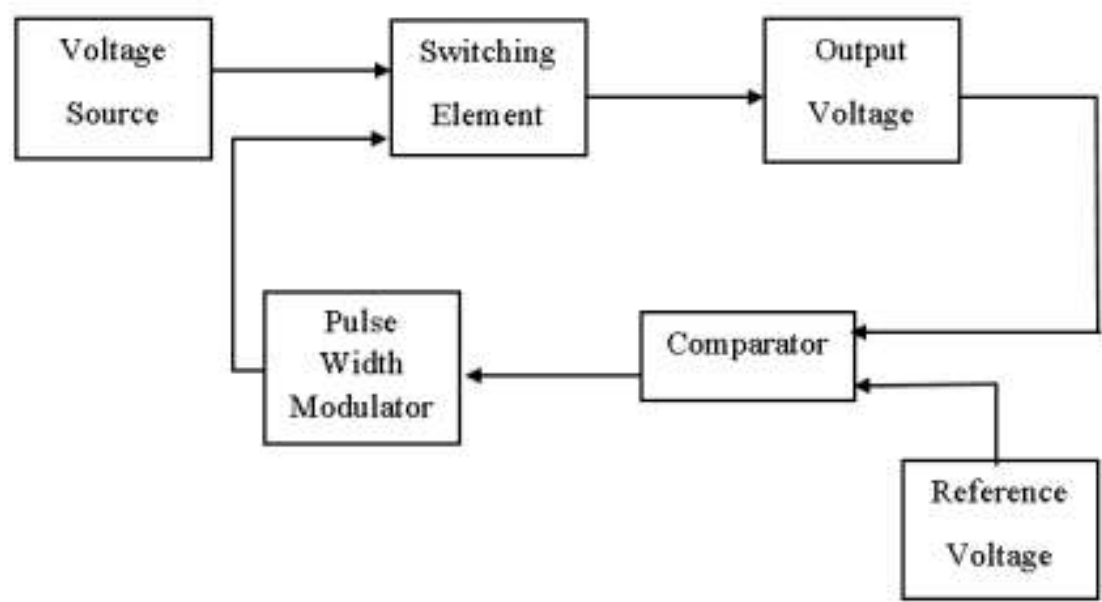

Figure 5. Block Diagram of Boost Converter

- The control algorithm changes the width based on the load voltage for high efficiency conversion and changes the gain value, for the output voltage regulation requirements.

- The width of the PWM directly depends on the output voltage comparison between the output voltage and the reference voltage (desired output voltage).

The basic flow diagram of a boost converter circuit:

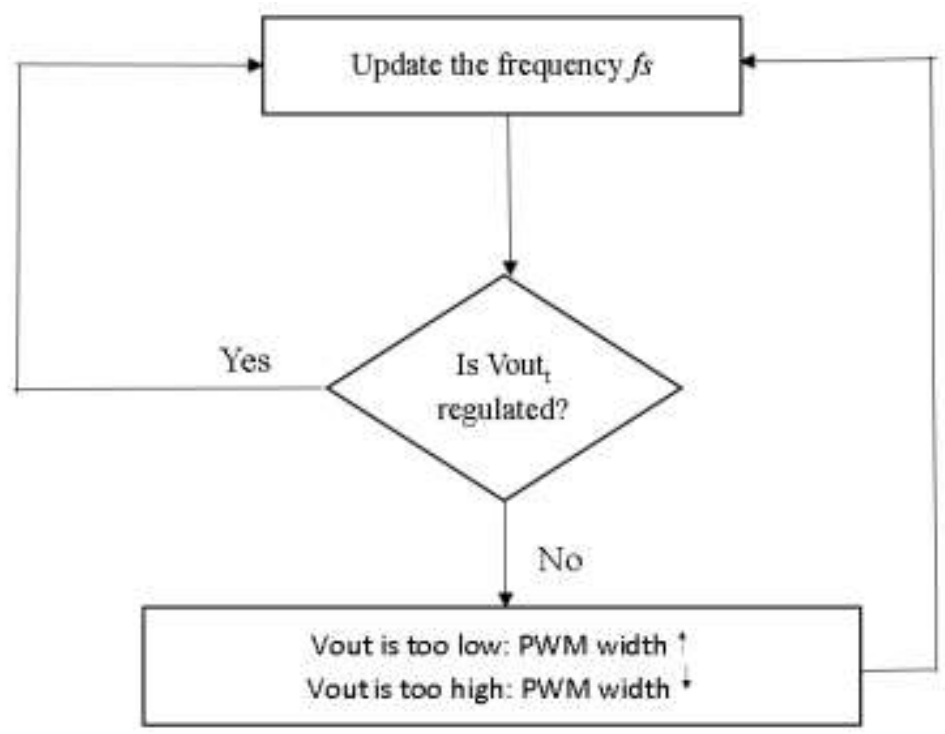

Figure 6. The Proposed Algorithm for Voltage Regulation at Near-Minimal Power Loss 


\section{Circuit Diagram and Waveform}

This is the basic diagram of DC-DC Boost converter where the rectangular pulse is connected to the NMOS for the switching purpose (ON/OFF).

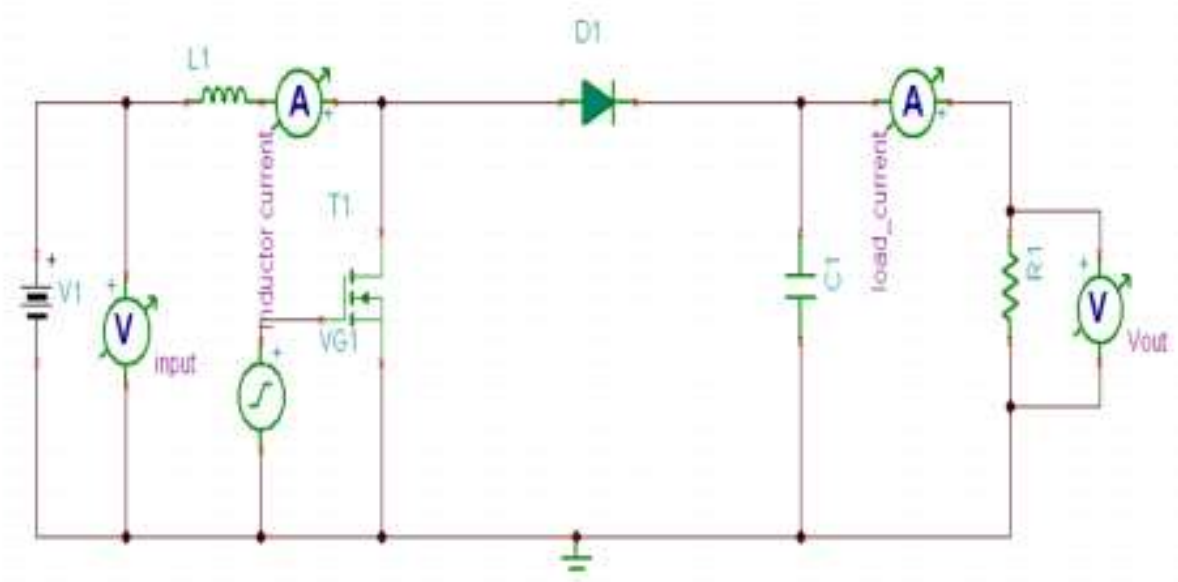

Figure 7. Circuit Diagram of Boost Converter used in PSPICE

This is the waveform generated for the input of $200 \mathrm{mV}$ for the constant output of $1 \mathrm{~V}$.

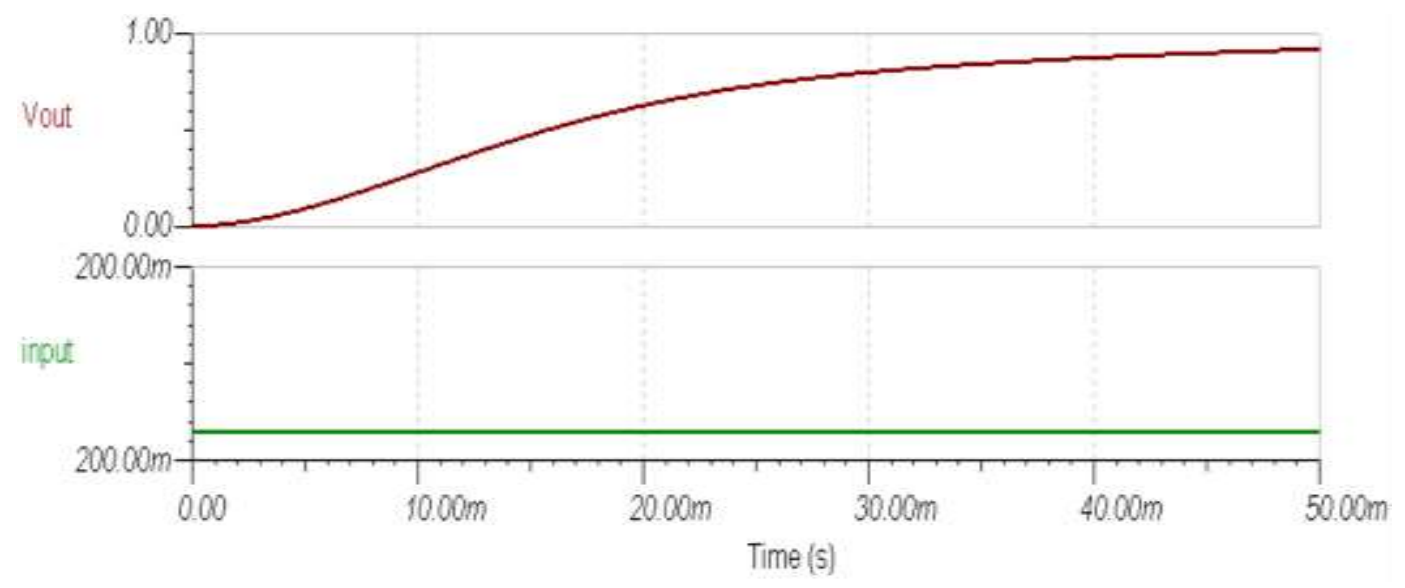

Figure 8. Waveform of Vout (output voltage) and Vin (input voltage)

Now considering the source which is connected to the gate terminal of NMOS is converted into the automatic control circuit which alters the width or duty cycle of the pulse in accordance with the output voltage measured across the load.

If the output voltage is greater or lesser than the reference voltage then the width or duty cycle reduced or increased as the output voltage remain close to the reference voltage.

Input Voltage 200mV and Output Voltage 1V with Pulse Width Modulator (PWM): 


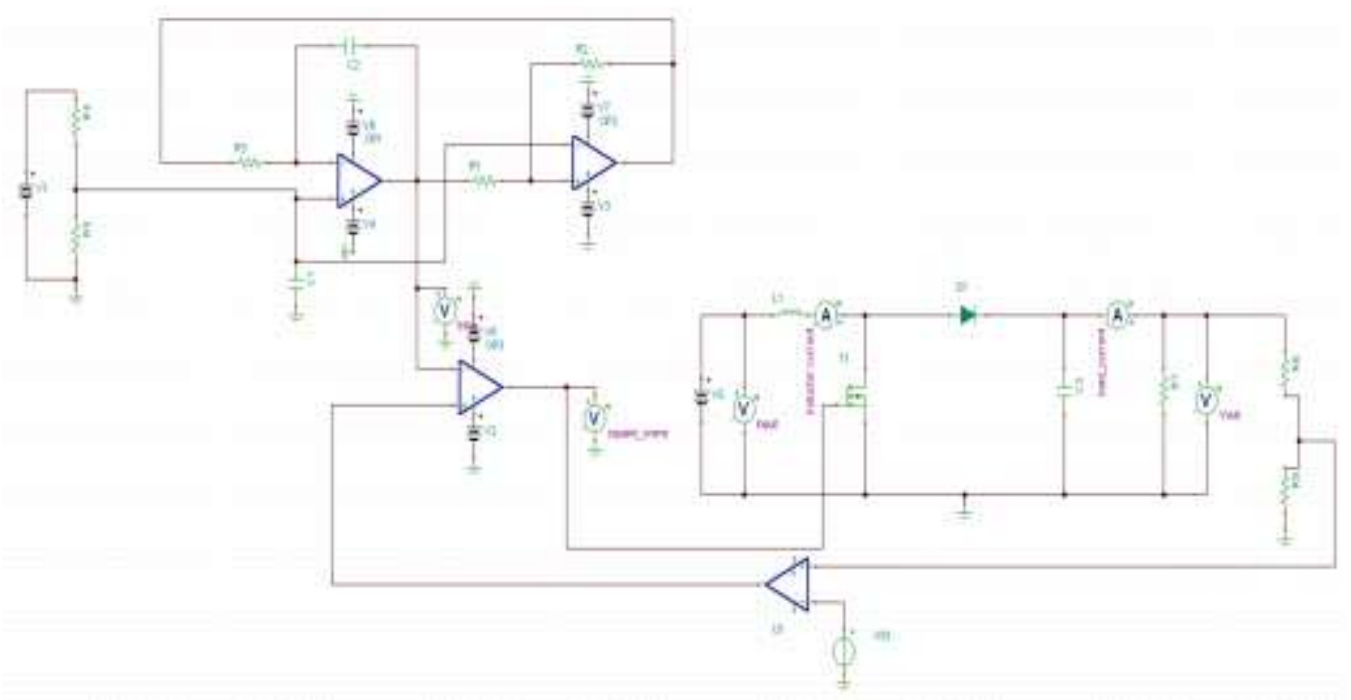

Figure 9.Circuit Diagram for Boost Convertor with PWM
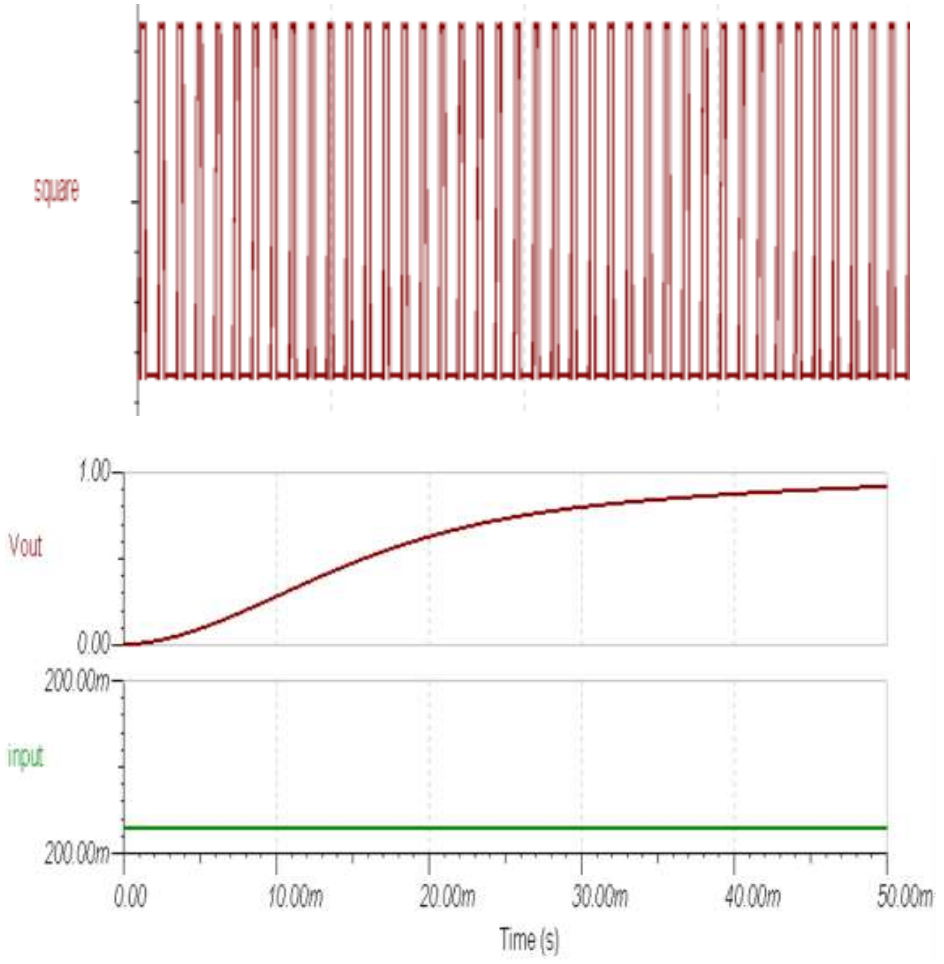

Figure 10. Waveform of Vout (output voltage) and Vin (input voltage) with PWM

The main aspect of energy harvesting is to sense the minimal voltage which is present in the environment basically a waste energy produced by the heating effect (temperature), vibration (from machines), motion etc. thereby designing a boost converter which boosts the minimal voltage is required in this emerging technology.

PWM generates the output directly dependent on the feedback from the output.

Pulse Width Modulator comprises of operational amplifier and comparator. Opamp circuit is made of CMOS planar technology which generates the triangular output which is compared with the input to generate the pulses of the different widths.

If the input supply voltage fluctuates (within the range) the PWM generates the pulse of suitable width and helps the boost converter to maintain the output voltage constant. 


\section{Conclusion}

Energy harvesting from waste source or ambient source promises new solutions for many applications in the biomedical, industrial and military fields as well as in consumer and industrial goods. All of the specifications stated previously have been met by this boost converter design usingwhich an ultra-less voltage of $200 \mathrm{mV}$ is boosted to $1 \mathrm{~V}$ with the help of external circuitry of PWM which controls the width of switching device.

\section{References}

[1] J. Kim and C. Kim, "A DC-DC Boost Converter With Variation-Tolerant MPPT Technique and Efficient ZCS Circuit for Thermoelectric Energy Harvesting Applications", IEEE trans., vol.62, no.2, (2015).

[2] E. J. Carlson, K. Strunz and B. P. Otis "A 20mV Input Boost Converter With Efficient Digital Control for Thermoelectric Energy Harvesting", IEEE journal of solid-state circuits, vol. 45, no. 4, (2010).

[3] J. Kim, J. Kim and C. Kim, "A regulated charge pump with a low-power integratedoptimumpowerpointtrackingalgorithmforindoorsolarenergy harvesting", IEEE Trans. Circuits Syst. II, Exp. Briefs, vol. 58, no. 12, (2011), pp. 802-806.

[4] H. Lhermet, C. Condemine, M. Plissonnier, R. Salot, P. Audebert and M. Rosset, "Efficient power management circuit: From thermal energy harvesting to above-IC microbattery energy storage", IEEE J. Solid-State Circuits, vol. 43, no. 1, (2008), pp. 246-255.

[5] H. Shao, X. Li, C.-Y. Tsui and K. Wing-Hung, "A Novel Single-Inductor Dual-Input Dual-Output DCDC Converter With PWM Control for Solar Energy Harvesting System”, IEEE Trans on very large scale integration (VLSI) systems, vol. 22, no. 8, (2014).

[6] Y. K. Ramadass and A. P. Chandrakasan, "A batteryless thermoelectric energy-harvesting interface circuit with $35 \mathrm{mV}$ startup voltage”, IEEE J. Solid-State Circuits, vol. 46, no. 1, (2011), pp. 333-341.

[7] J.-P. Im, S.-W. Wang, K.-H. Lee, Y.-J. Woo, Y.-S. Yuk, T.-H. Kong, S.-W. Hong, S.-T. Ryu and G.-H. Cho, "A $40 \mathrm{mV}$ transformer-reuse self-startup boost converter with MPPT control for thermoelectric energy harvesting", in Proc. IEEE Int. Solid-State Circuits Conf. Dig. Tech. Papers, (2012), pp. 104105.

[8] LT1070 Design Manual.

[9] Pulse-Width Modulator Features Versatile Operating Parameters | Power content from Electronic Design

[10] A. Pradeep Kumar Yadav1, S. Thirumaliah2 and G. Haritha, "Comparison of MPPT Algorithms for DCDC Converters Based PV Systems", International Journal of Advanced Research in Electrical, Electronics and Instrumentation Engineering, vol. 1, Issue 1, (2012).

[11] Y. K. Ramadass and A. P. Chandrakasan, "Voltage Scalable Switched Capacitor DC-DC Converter for Ultra-Low-Power On-Chip Applications", Massachusetts Institute of Technology Cambridge, MA 02139 USA.

[12] P.-H. Chen and P. M.-Y. Fan, “An 83.4\% Peak Efficiency Single-Inductor Multiple-Output Based Adaptive Gate Biasing DC-DC Converter for Thermoelectric Energy Harvesting", IEEE trans. on circuits and system-I: regular papers, vol.62, no. 2, (2015).

[13] Basic Calculation of a Boost Converter's Power Stage- SLVA372C-November 2009-Revised January 2014.

[14] M. H. Rashid, "Power Electronics, Circuits, Devices and Applications", Third Edition, Pearson Education, Inc., (2004).

[15] C. Nelson and J. Williams, "Linear Technology, LT1070 Design Manual”, 1986.

[16] Marty Brown, "Practical Switching Power Supply Design", New York: Academic Press, Inc., (1990).

[17] I. M. Gottlieb, "Power Supplies, Switching Regulators, Inverters, \& Converters", New York: McGrawHill, (1993).

[18] D. M. Mitchell, "DC-DC Switching Regulator Analysis", New York: McGraw-Hill, (1988).

[19] A. Soni, "DC-DC Switching Boost Converter", ILLINOIS College of Engineering, (1999).

[20] G. Seguier, "Power Electronic Converters: DC-DC Conversion", New York, Springer Verlag, Inc., (1993).

[21] A. P Prem, S. Govind and C. P. Ravi, "Zero-Voltage and Zero-Current Switching Buck-Boost Converter for PV Applications", IJCSNS International Journal of Computer Science and Network Security, vol.14 no.12, (2014). 


\section{Authors}

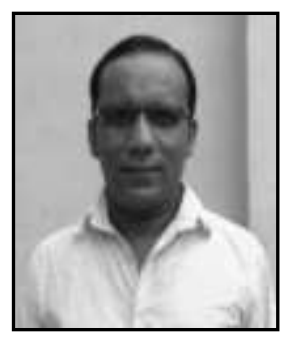

Bal krishan, he Assistant Professor, Electronics Engineering Department, YMCA University of Science and Technology, Faridabad, Haryana-121006, India; B.E. (Electronics \& Communication Engineering: DCRUST Murthal, Sonepat, Haryana, India), M. Tech. (Nanotechnology: Jamia Milia Islamia Central University, Delhi, India), Ph. D. (pursuing in Nanoelectonics). He has published 28 numbers of papers in various International \& National Journals \& conferences. His Areas of research: Nanoelectronics \& Devices, VLSI Design, Electronics Engineering.

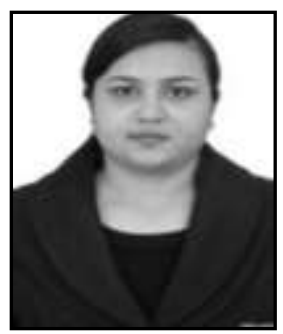

Yogita, she enrolled her Electronics and Communication Engineering: Shri Mata Vaishno Devi University, Jammu, India), M. Tech. (VLSI Design: YMCA University of Science and Technology, Faridabad, Haryana-121006, India). She has published many papers in various International \& National Journals. Her Areas of research: VLSI Design, Electronics Engineering. 
International Journal of Control and Automation

Vol. 11, No. 1 (2018) 